\title{
Neocolonialismo da Educação no Rio de Janeiro: a política pública de padronização do processo ensino-aprendizagem.
}

\author{
Neocolonialismo de la Educación en Río de Janeiro: la política pública de \\ la normatización del proceso de enseñanza-aprendizaje. \\ Neocolonialism of Education in Rio de Janeiro: the public policy of \\ normalization of the teaching-learning process.
}

\author{
Dr. Washington Kuklinski Pereira ${ }^{1}$
}

\begin{abstract}
Resumo
As políticas públicas de educação ao redor do mundo estão passando por um processo de padronização internacional. O sistema PISA (Programme for International Studant Assiment), que conta atualmente com a participação de 32 países, promove testes internacionais com o objetivo de estabelecer níveis de aprendizado. Para tanto, são criados sistemas genéricos de avaliação que desprezam as particularidades de cada região analisada. Além disso, há a proposta de mecanização do conhecimento, sendo estabelecidos apenas parâmetros para mensurar pseudo competências sobre o entendimento de Ciências, Matemática e a capacidade de leitura dos estudantes. Muitos países são signatários do sistema PISA. Sendo assim, as políticas públicas destes passaram a estabelecer metas que direcionam o processo ensino-aprendizagem a uma padronização internacionais e desprezam a formação crítica do indivíduo. Inspirada no sistema PISA, no ano de 2009, a prefeitura do Rio de Janeiro criou a Prova Rio. Desde então, a Secretaria Municipal de Educação busca, a partir de um sistema genérico, estabelecer o nível de aprendizagem, nas disciplinas de Português, Matemática e Ciências, dos discentes inscritos regularmente na rede municipal de educação do Rio de Janeiro. A partir desta perspectiva, o trabalho tem como objetivo discutir as políticas públicas do Neoconialismo da educação, tendo como foco o exemplo da cidade do Rio de Janeiro. Além disso, propõe estimular práticas de decolonização da educação como forma de resistência a essa política pública de educação.
\end{abstract}

Palavras-chave: Neocolonialismo da Educação; Decolonialização da Educação; Rio de Janeiro.

\section{Resumen}

Las políticas de la educación pública en todo el mundo están experimentando un proceso de normalización internacional. El sistema de PISA (Programa Internacional de Estudiante Assiment), que actualmente cuenta con la participación de 32 países, promueve los testes internacionales con el fin de establecer los niveles de aprendizaje. Por lo tanto, los genéricos se crean sistemas de evaluación que hacen caso omiso de las particularidades de cada región analizada. Además, existe la propuesta de la mecanización del conocimiento, simplemente está estableciendo parámetros para medir las habilidades en las escuelas, apuntando los niveles en Ciencias, en las matemáticas y la capacidad de lectura de los estudiantes. Muchos países son signatarios del sistema de PISA. Estas políticas públicas comenzaron a establecer objetivos que guían el proceso de enseñanzaaprendizaje mediante la estandarización de las normas internacionales y desprecian la formación crítica del individuo. Inspirado por el sistema de PISA, en 2009, la ciudad de Río de Janeiro constituyó la prueba del río. Desde entonces, la búsqueda Municipal de Educación, a partir de un sistema genérico, establecer el nivel de aprendizaje, en Portugués, Matemáticas y Ciencias, inscrito de forma regular a los estudiantes en la red municipal de educación en Río de Janeiro. El presente trabajo pretende analizar las políticas públicas Neoconialismo de la educación, centrándose en el ejemplo de la ciudad de Río de Janeiro. También se propone fomentar las prácticas de descolonización de la educación como una forma de resistencia a este tipo de educación política pública.

\footnotetext{
${ }^{1}$ Doutor em História pela Pontifícia Universidade Católica de São Paulo; Professor da Fundação de Estudos do Mar;Professor da Secretaria Municipal de Educação do Rio de Janeiro, atuando nas escolas Frei Gaspar e Comunidade Vargem Grande; Contato: prof.washington.kuklinski@gmail.com; Trabalho apresentado no I Seminário Latino-Americano de Estudos em Cultura - SEMLACult, Foz do Iguaçu/PR, Brasil, 2017.
} 
Palabras claves: Neocolonialismo de la Educación; Descolonialización de la Educación; Rio de Janeiro.

\begin{abstract}
The public education policies around the world are undergoing an international standardization process. The PISA system, which currently has the participation of 32 countries, promotes international testing in order to establish learning levels. Therefore, generics are created evaluation systems that ignore the particularities of each region analyzed. In addition, there is the proposal of the mechanization of knowledge, is simply establishing parameters to measure skills in schools, pointing out the levels in science, mathematics and reading ability of students. Many countries are signatories to the PISA system. These public policies began to establish objectives that guide the teaching-learning process through the standardization of international norms and despise the critical formation of the individual. Inspired by the PISA system, in 2009, the city of Rio de Janeiro was the test of the river. Since then, the Municipal Education search, based on a generic system, establish the level of learning, in Portuguese, Mathematics and Science, regularly enrolled students in the municipal net of education in Rio de Janeiro. The present paper aims to analyze public policies Neoconialism of education, focusing on the example of the city of Rio de Janeiro. It is also proposed to promote decolonization practices in education as a form of resistance to this type of public policy education.
\end{abstract}

Keywords: Neocolonialism of Education; Decolonialization of the Education; Rio de Janeiro.

1. A padronização internacional da Educação.

\author{
"Fundadores e colonizadores do Império do \\ Brasil tinham os olhos na Europa e os pés na \\ América (...)" (MATTOS, 1999, p. 116)
}

A reflexão feita por Ilmar de Mattos, na obra O Tempo Saquarema, nos serve de premissa inicial para pensarmos os pilares das políticas públicas de Educação do Brasil. "De costas" para os próprios saberes de seu povo, forjou-se um projeto educacional que tenta "padronizar" o processo de ensino-aprendizagem, a fim de seguir um modelo educacional europeu, negando, ao máximo, as características culturais e os saberes multiétnicos formadoras de uma "colcha de retalhos" chamada população brasileira.

Entre 1962 e 1986, França, Irlanda, Hungria, Suécia e o Reino Unido criaram sistemas próprios para mensurar o desenvolvimento do processo de ensino-aprendizagem. $\mathrm{O}$ objetivo inicial era fornecer dados para os professores sobre a "adequação" das aulas com o currículo comum nacional. A partir da década de 1990, as criações dos testes nacionais se espalharam pela Europa ${ }^{2}$. Apenas em 1997, surgiu a ideia de normatizar um único sistema de testes de

\footnotetext{
${ }^{2}$ National Testing of Pupils in Europe: Objectives, Organisation and Use of Results. Education, Audiovisual and Culture Executive Agency, 2009 disponível em:http://www.eurydice.org
} 
aprendizagem para um grupo amplo de países, o qual foi aplicado pela primeira vez no ano de 2000 .

Assim como ocorria na Europa, as políticas públicas de educação ao redor do mundo passaram e estão passando pelo mesmo processo de padronização internacional. Para tanto, o sistema PISA (Programme for International Studant Assiment), que conta atualmente com a participação de 32 países, promove testes internacionais com o objetivo de estabelecer níveis de aprendizado ${ }^{3}$. Dessa forma, são criados sistemas genéricos de avaliação que desprezam as particularidades de cada região analisada. Além disso, há a proposta de mecanização do conhecimento, sendo estabelecidos apenas parâmetros para mensurar pseudo-competências sobre o entendimento de Ciências, Matemática e a capacidade de leitura dos estudantes.

Nesse processo de padronização internacional de testes educacionais, muitas nações da América Latina se tornaram signatárias do sistema PISA, tais como: Brasil, Chile, Colômbia, Costa Rica, México, Peru, República Dominicana e Uruguai. Sendo assim, as políticas públicas destes países passaram a estabelecer metas que direcionam o processo ensino-aprendizagem a uma formação genérica que atenda aos parâmetros internacionais e despreze a formação crítica do indivíduo.

Especificamente no caso brasileiro, a primeira proposta de teste padronizado para mensurar as competências dos estudantes da educação básica foi o Exame Nacional do Ensino Médio (ENEM), aplicado pela primeira vez no ano de 1998. Em 2010, através da criação do Sistema de Seleção Unificada (SiSU), esse exame se tornou o principal instrumento para o ingresso de estudantes em universidades que usam os dados da prova para substituir o vestibular.

No decorrer do segundo mandato do governo do presidente Fernando Henrique Cardoso (1998-2002), testes padronizados foram parte substancial do projeto educacional do país. Por isso, em 2000, primeiro ano de aplicação das provas do sistema PISA, pouco tempo após a criação do ENEM, o Brasil já fazia parte do Programme for International Studant Assiment.

2. A neocolonialide nas políticas públicas de educação na cidade do Rio de Janeiro.

\footnotetext{
${ }^{3}$ Dados disponíveis em: http://www.oecd.org/pisa/
} 
Em 2009, no primeiro ano de mandato, o então prefeito da cidade do Rio de Janeiro, Eduardo Paes, o sistema PISA também inspirou a criação de um modelo educacional tornandose parâmetro da política educacional do município. Assim, no ano de 2009, a prefeitura do Rio de Janeiro criou a Prova Rio ${ }^{4}$. A aplicação da prova é geralmente dividida em três dias. Assim como propõe o modelo internacional, os estudantes respondem questões sobre Língua Portuguesa, Matemática e Ciências.

Para atingir as metas indicadas pelo sistema Prova Rio, inúmeros instrumentos surgiram com o objetivo de nortear o trabalho docente. A proposta do governo Eduardo Paes era possibilitar a padronização de um processo ensino-aprendizagem mecanizado em toda a rede pública escolar carioca. Como os resultados iniciais estavam abaixo do estimado pelo poder público, foram criados mecanismos para que os professores das disciplinas envolvidas treinassem os estudantes para atingirem as metas indicadas como ideais pela prefeitura.

Nesse sentido, foi criado um sistema apostilado das disciplinas, o qual segue os parâmetros curriculares nacionais, com o conteúdo elementar para ser desenvolvido, dividido em oito propostas semanais, a serem aplicadas em cada bimestre. Ao término da oitava proposta, as escolas devem aplicar um teste bimestral comum para toda a rede, seguindo um calendário único. São ao total quinze questões de múltipla escolha para cada disciplina. Os alunos devem preencher um cartão resposta, destacá-lo da prova e entregar ao professoraplicador. Os dados dos cartões são inseridos em um sistema online que alimenta um banco de dados da Secretaria de Educação, gerando, assim, informações sobre o desempenho de cada escola, de cada região e do município como um todo.

O uso de um sistema apostilado, com a aplicação de um teste bimestral em comum, não foi a única iniciativa para o projeto de padronização do processo ensino-aprendizagem na rede municipal da cidade do Rio de Janeiro. No ano de 2010, a prefeitura desenvolveu a plataforma online Educopédia ${ }^{5}$. O sistema é organizado por disciplina, ano de escolaridade e tema do conteúdo programático proposto pela prefeitura, a partir da orientação curricular. O objetivo da plataforma é direcionar os docentes para a preparação dos alunos na execução das provas bimestrais e, conseqüentemente, para a Prova Rio.

\footnotetext{
${ }^{4}$ Disponível em: http://prefeitura.rio/web/smeel/exibeconteudo?id=6265862

${ }^{5}$ http://www.educopedia.com.br/
} 
RELACult - Revista Latino-Americana de Estudos em Cultura e Sociedade

Revista Latinoamericana de Estudios en Cultura y Sociedad | Latin American Journal of Studies in Culture and Society V. 03, ed. especial, dez., 2017, artigo $\mathrm{n}^{\circ} 470$ | relacult.claec.org | e-ISSN: 2525-7870

(2) wnw.educopedia.com.br $x$

$\leftarrow \rightarrow$ C (1) Não seguro $\mid$ www.educopedia.com.br

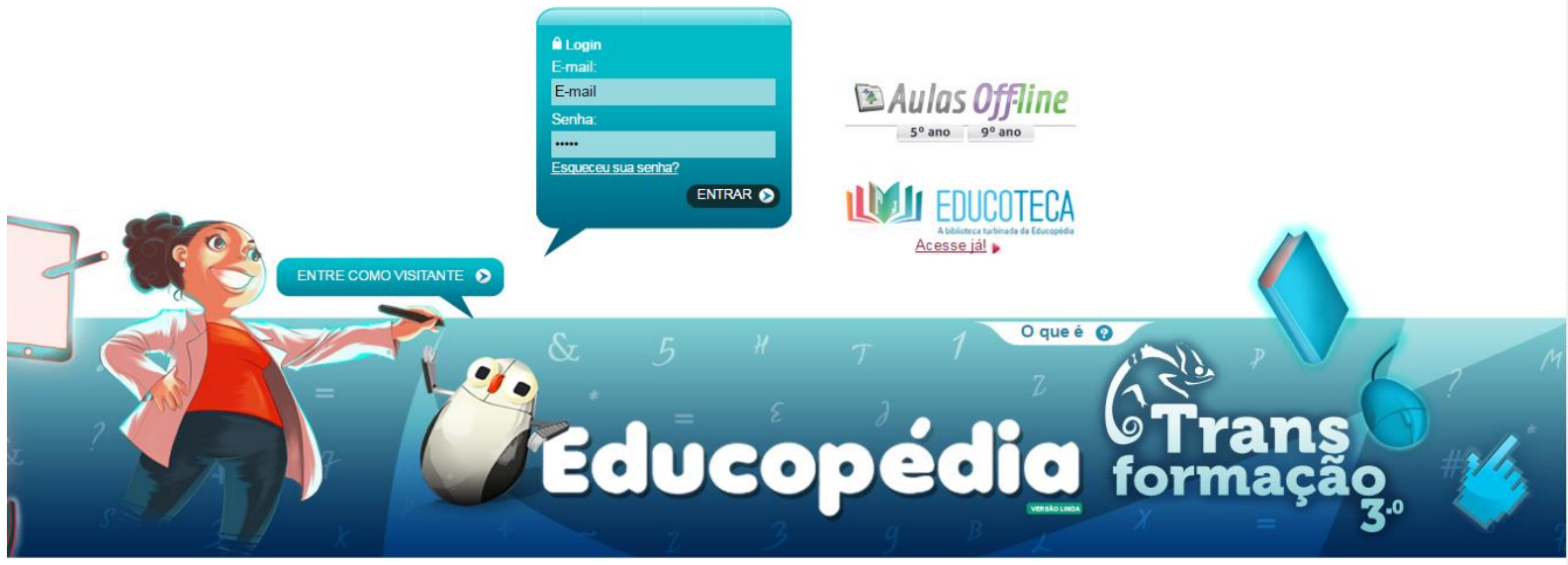

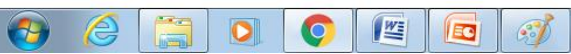

(Página Inicial da plataforma Educopédia)

Após acessar a página inicial e fazer o login, como professor da rede ou como visitante, o usuário do sistema acessa uma área em que escolhe qual o ano escolar sobre o qual pretende buscar as informações:

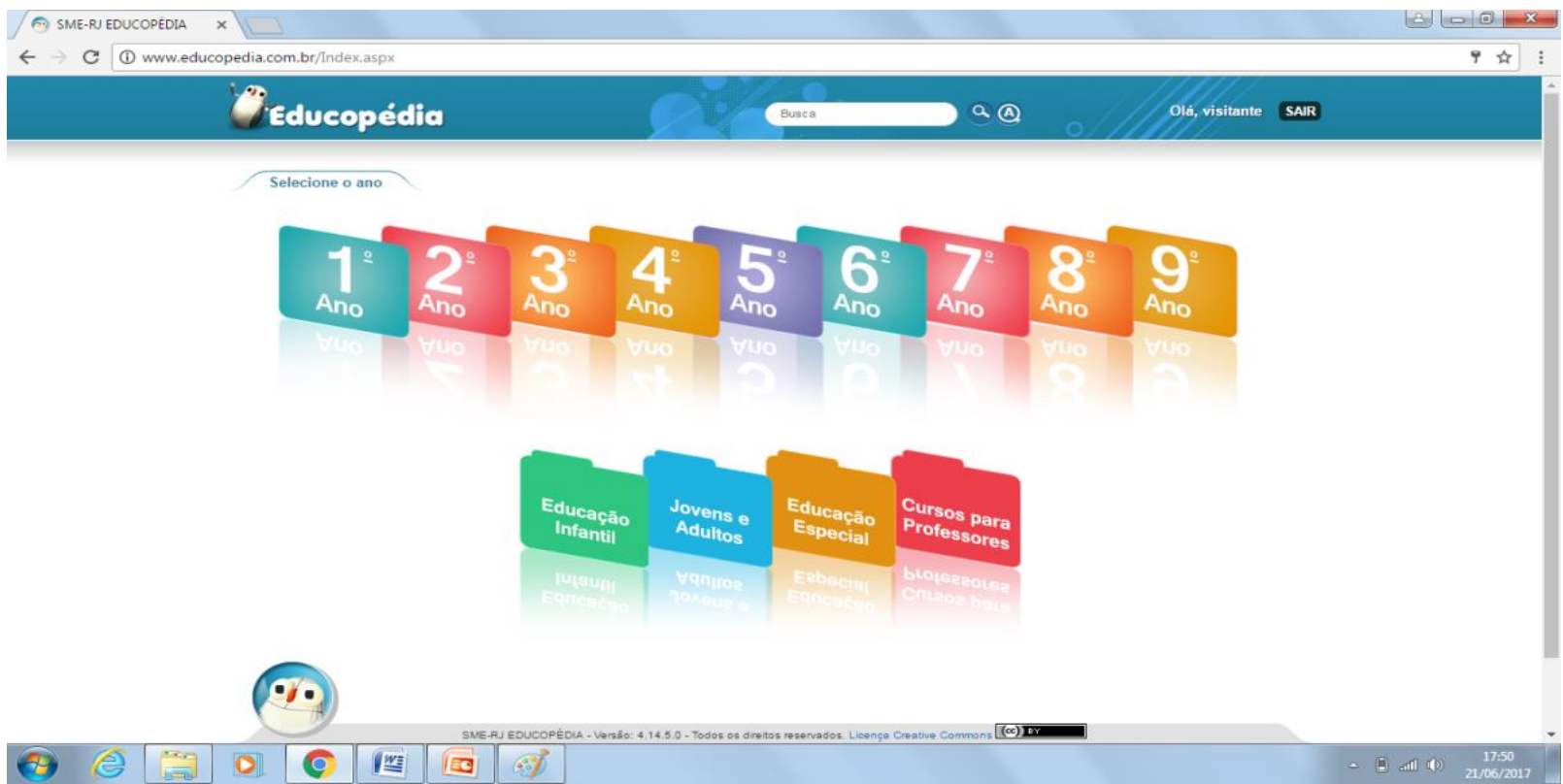

(Imagem retirada da plataforma Educopédia)

Posteriormente, é encaminhado para o quadro de disciplinas oferecidas como eletivas e obrigatórias pela rede municipal de educação: 
RELACult - Revista Latino-Americana de Estudos em Cultura e Sociedade

Revista Latinoamericana de Estudios en Cultura y Sociedad | Latin American Journal of Studies in Culture and Society V. 03, ed. especial, dez., 2017, artigo $\mathrm{n}^{\circ} 470$ | relacult.claec.org | e-ISSN: 2525-7870

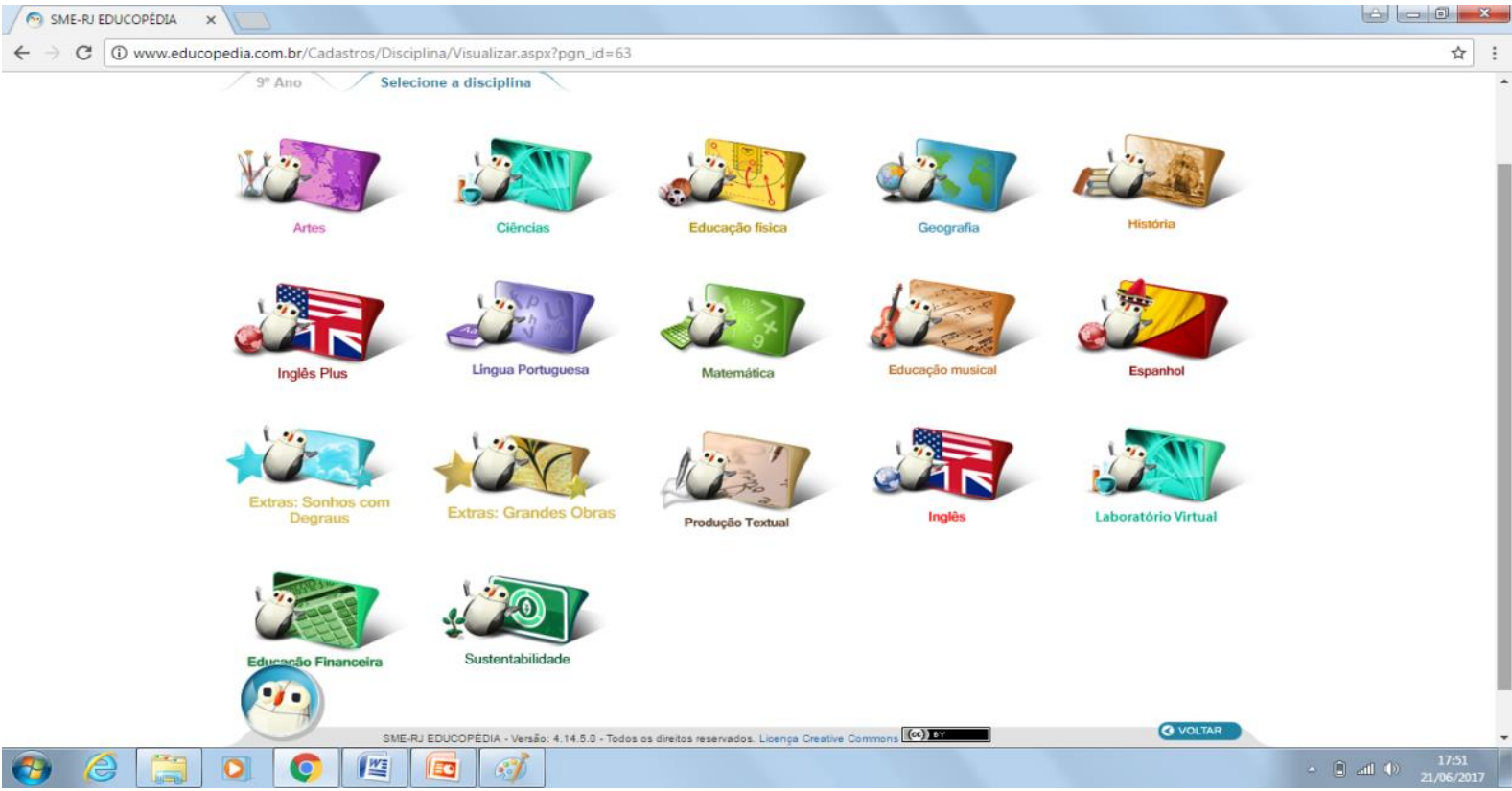

(Imagem retirada da plataforma Educopédia)

Após essa etapa, o professor elege uma das oito propostas bimestrais da disciplina de interesse, podendo assim fazer o download de planos de aula e de apresentações em slides previamente disponibilizadas na plataforma:

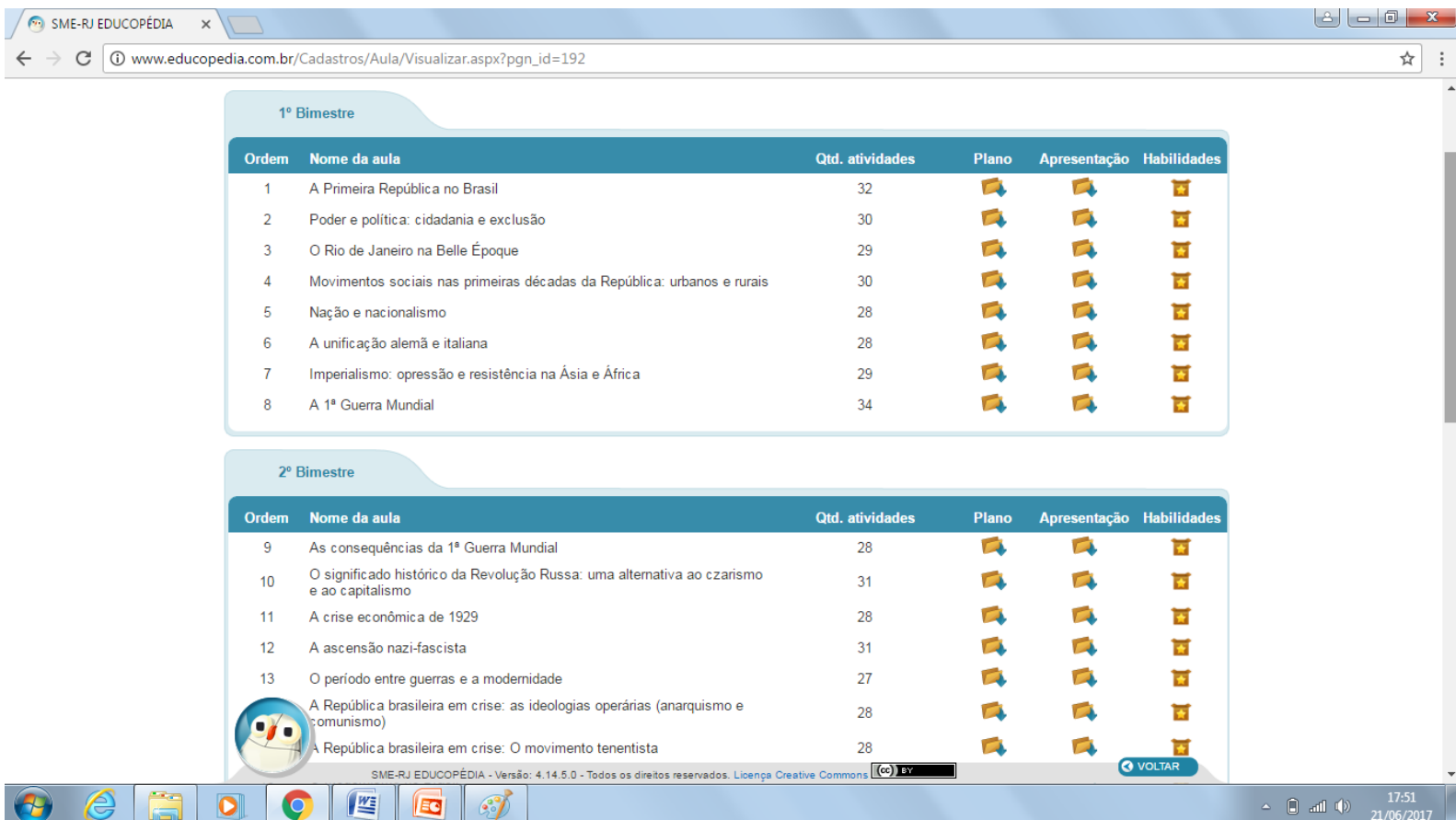

(Imagem retirada da plataforma Educopédia) 
Os professores de todas as disciplinas passaram a ter acesso a um banco de dados onde poderiam obter planos de aula, exercícios e apresentações de aulas já prontas em slides. Os planos de aula, se seguidos pelos docentes, transformam a mediação do processo ensinoaprendizagem por parte do professor em uma atividade mecânica de aplicação de métodos. Dessa maneira, despreza as particularidades de cada realidade escolar e de cada discente, ocasionando a formação de estudantes e docentes passivos perante um aprendizado bancário.

No ano de 2009, com o objetivo de promover a política educacional que iniciaria nesse mesmo ano, houve a distribuição de notebooks para os professores recém chegados à rede municipal de educação. Mesmo oferecendo uma metodologia própria para condicionar os alunos à execução da Prova Rio, as escolas não tinham suporte técnico para a aplicabilidade da plataforma Educopédia. Por isso, as unidades escolares receberam aparelhos de notebook e foram instalados equipamentos projetores e roteadores de internet wi-fi ${ }^{6}$ na maioria delas. Entretanto, a adesão ao Educopédia pelos professores era considerada pequena.

Objetivando a ampliação da aplicação dos métodos promovidos pela política pública de educação municipal, os concursos públicos para professores ingressantes a partir de 2012 passaram a exigir novas etapas para o processo de aprovação. Na primeira etapa classificatória, os candidatos respondem questões de múltipla escolha e uma única questão dissertativa. Posteriormente, ocorre o somatório dos pontos de títulos de pós-graduação, mestrado, doutorado e pós-doutorado ${ }^{7}$.

Ao término do cômputo das notas, os candidatos são convocados para um treinamento obrigatório e remunerado. Essa etapa tem a duração de duas semanas e ocorre nas dependências da Escola de Formação do Professor Carioca - Paulo Freire. Contendo palestras e oficinas oferecidas no período matutino e vespertino, o curso possui uma carga horária total de oitenta horas $^{8}$.

Um dos requisitos para a aprovação do candidato nessa etapa do concurso e a consequente remuneração pelo período é a frequiência de noventa porcento das atividades. Além

\footnotetext{
${ }^{6}$ A maioria dos roteadores são bloqueados para acesso por aparelhos telefônicos e tablets. Além disso, alguns sites também são bloqueados, como por exemplo, Youtube. Uma das conseqüências disso é a impossibilidade de acessar vídeos propostos pela própria plataforma Educopédia.

${ }^{7}$ A Prefeitura Municipal do Rio de Janeiro reconhece oficialmente os títulos de pós-doutorado para o plano de carreira dos seus servidores.

${ }^{8}$ Para alguns editais de processos seletivos opta-se por uma carga horária de 40 horas, dividida em uma semana.
} 
de expor a estrutura da Secretaria Municipal de Educação, abordar questões relacionadas sobre a carreira e as condições de trabalho nas escolas, o principal objetivo do curso é preparar o candidato para a etapa final do processo seletivo: uma prova didática.

Nesse sentido, para promover a política pública de educação municipal, os candidatos têm contato com o sistema apostilado. Também é feito um treinamento sobre a plataforma Educopédia e são apresentados outros instrumentos para o condicionamento de uma padronização do processo de ensino-aprendizagem. Com esse objetivo, ocorre a distribuição da obra Aula Nota Dez: 49 técnicas para ser um professor campeão de audiência, do autor estadunidense Doug Lemov (2011), para os candidatos que estão na última etapa do processo seletivo docente da rede municipal de educação do Rio de Janeiro.

As atividades com maior tempo de desenvolvimento, totalizando a carga horária de oito horas cada, são os treinamentos sobre os materiais desenvolvidos pela empresa de mídia MultiRio, a plataforma Educopédia e as técnicas do livro Aula nota dez(...).

A abordagem da obra de Doug Lemov é totalmente direcionada para a aplicabilidade das técnicas apontadas pelo autor no decorrer do livro. Dentre elas, a técnica 11: "Faça o Mapa" é talvez a que melhor representa o projeto político pedagógico de Lemov:

\footnotetext{
"Independente do esquema que você use, onde colocar as carteiras é tão importante quanto determinar os 'corredores' e as 'fileiras'. Na verdade, enquanto está dando a aula, você deve poder chegar a qualquer lugar da sala sem precisar pronunciar uma palavra (preferivelmente à distância de 30 centímetros de qualquer aluno, de maneira que você possa cochichar no ouvido dele sem precisar curvar-se sobre outro aluno). Se você precisar dizer 'com licença' para que um aluno empurre a cadeira ou mude a mochila de lugar, de forma que você possa chegar onde quer, você estará basicamente pedindo autorização. Você vai ter de interromper sua aula para chegar aonde quer na sala. Com isso, você terá cedido o controle da sala de aula e inviabilizado o seu acesso a toda as partes da sala ${ }^{9}$. Isso limita a sua capacidade de cobrar elevados padrões acadêmicos e de comportamento de sues alunos. Portanto, independentemente da disposição de carteiras que você escolha, pense seriamente sobre fileiras e corredores também." (LEMOV, 2011, p. 87) (grifo meu)
}

Ao propor esse tipo de estrutura para a sala de aula, transformando o professor na única autoridade, Lemov exclui qualquer possibilidade de contato entre professor e estudante, principalmente no que se refere ao papel desempenhado por ambos no processo de ensinoaprendizagem. O protagonismo do professor, segundo o autor, já deve estar presente desde a

\footnotetext{
${ }^{9}$ Grifos meus.
} 
arrumação da sala até uma possível aproximação entre docente e discente, a fim de evitar que o primeiro, de maneira educada, solicite criação de espaço ao segundo.

Ao criar essa condição de relação entre estudantes e educadores, Doug Lemov propõe que o ambiente pedagógico permaneça com a estrutura de uma educação tradicional, balizada nos princípios epistemológicos da educação bancária ${ }^{10}$. Dessa maneira, o trabalho docente se torna um instrumento transformador do estudante em um depósito de informações. Esse ambiente também possibilita que os discentes sejam condicionados a executar tarefas que aproximem da realidade das práticas dos testes padronizados, criando assim indivíduos detentores de informações que não desenvolvem seus múltiplos talentos, competências e habilidades, descartando a possibilidade de valorizar o conhecimento prévio do estudante, inviabilizando o processo ensino-aprendizagem crítico.

Talvez, por princípios ideológicos, muitos professores ainda resistam ao processo de mecanização das suas aulas com o intuito de promover avanços nos índices da Prova Rio. Nesse sentido, ainda foi criado um mecanismo econômico de premiação de todos os professores das unidades escolares que atingirem as metas propostas pela Secretaria Municipal de Educação. O estímulo financeiro, chamado pelos docentes de "décimo quarto salário", tem como parâmetro os resultados da Prova Rio, sendo também necessário atingir outros índices, como o Índice de Desempenho da Educação Básica (IDEB).

\section{Considerações Finais}

Em uma cidade com aproximadamente 6,5 milhões de habitantes, distribuídos em $5265,82 \mathrm{~km}^{211}$, o Rio de Janeiro é um município multicultural. Sua população é formada pelos nascidos na própria cidade, por pessoas de outros municípios do Estado, por migrantes de outros Estados e ainda por imigrantes de todo o mundo. Essa realidade multicultural é refletida no interior das escolas.

A Estrutura da Secretaria Municipal de Educação é volumosa, sendo uma das maiores redes públicas de ensino da América Latina. São 1.537 unidades escolares; 651.655 alunos matriculados; 41.302 docentes; 15.191 funcionários de apoio e administrativos ${ }^{12}$. Com essa

\footnotetext{
${ }^{10}$ Conforme denominada por Paulo Freyre a pedagogia tradicional.

${ }^{11}$ Dados disponíveis em: http://cidades.ibge.gov.br/xtras/perfil.php?codmun=330455

12 http://prefeitura.rio/web/smeel/educacao-em-numeros
} 
realidade, promover a padronização do processo ensino-aprendizagem requer o desprezo dos múltiplos conhecimentos adquiridos pelos estudantes e docentes no decorrer da experiência de vida de cada um.

Ainda assim, a Secretaria Municipal de Educação aprofunda suas políticas públicas no sentido de estabelecer um sistema genérico, com uma metodologia bancária para preparar os estudantes a atingir níveis considerados desejáveis na Prova Rio, consequentemente, preparando-os para os testes do Programme for International Studant Assiment. Portanto, a Secretaria Municipal de Educação do Rio de Janeiro passou a estimular o modelo de Educação Bancária em detrimento ao fomento do pensamento crítico em suas unidades escolares.

Ao assumir como política pública de educação modelos conceituais desenvolvidos em outra realidade, desprezando as características dos habitantes da municipalidade, a educação pública da cidade do Rio de Janeiro tornou-se um grande laboratório de práticas educacionais em meio a um processo neocolonial da educação internacional. Dessa forma, os ensinamentos de Paulo Freire, intelectual da decolonialidade da educação no Brasil, foram abandonados em nome de um modelo de educação que mantém os "condenados da terra"13 em sua condição.

\footnotetext{
${ }^{13}$ Expressão utilizada por Frantz Fanon e apropriada por Paulo Freyre para também se referir aos oprimidos.
} 


\section{Referências}

ARAÚJO, Sônia Maria da Silva. Educação do Campo no Brasil: um discurso para além do pós-colonial? Rev.latinoam.cienc.soc.niñez juv 8(1). P.221-242.

ARROYO, Miguel. Outros Sujeitos, Outras Pedagogias. Petrópolis, RJ: Vozes, 2012.

BHABHA, Homi K. O local da cultura. Ed. UFMG: Belo Horizonte, 2005.

FANON, Frantz. Os Condenados da Terra. $2^{\text {a }}$ Ed. Rio de Janeiro: Civilização Brasileira, 1979.

FREIRE, Paulo. A educação como prática da liberdade. 23ª ed. Rio de Janeiro: Paz e Terra, 1999.

. Pedagogia da autonomia: saberes necessários à prática educativa. $43^{\mathrm{a}}$ ed., São

Paulo: Paz e Terra, 2011.

Pedagogia da esperança: um reencontro com a pedagogia do oprimido. Rio de

Janeiro: Paz e Terra, 2005.

. Pedagogia da indignação: cartas pedagógicas e outros escritos. $1^{\mathrm{a}}$ ed. São Paulo:

Editora UNESP, 2000.

FREIRE, Paulo; SHOR, Ira. Medo e ousadia: o cotidiano do professor. $5^{\mathrm{a}}$ edição. Rio de

Janeiro: Paz e Terra, 1986. 
GROSFOGUEL, Ramón. Decolonizing Post-Colonial Studies and Paradigms of Political Economy: Transmodernity, Decolonial Thinking, and Global Coloniality.

TRANSMODERNITY: Journal of Peripheral Cultural Production of the Luso-Hispanic World, School of Social Sciences, Humanities, and Arts, UC Merced. Disponível em: http://escholarship.org/uc/item/21k6t3fq Acesso em: 01/04/2017

LEMOV, Doug. Aula nota 10: 49 técnicas para ser um professor campeão de audiência. 4. ed. Porto Alegre: Penso, 2016.

MATTOS, Ilmar Rohloff de. O Tempo Saquarema: a formação do Estado Imperial. Rio de Janeiro: Access-Editora, 1999.

MORAIS, Regis de. Sala de aula: que espaço é esse? Ed. Papirus, 1994.

NETO, João Colares da Mota. Paulo Freire e o pós-colonialismo na educaçãoPopular latinoamericana. Revista Educação Online nº 14, p.25-38 , ago./dez. de 2013.

NOVASKI, Augusto João Crema. Sala de aula: uma aprendizagem do humano. In.: MORAIS, Regis de. Sala de aula: que espaço é esse? Ed. Papirus, 1994.

SILVA, Tomaz Tadeu da. Documentos de identidade: uma introdução às teorias do currículo. Belo Horizonte: Autêntica, 2009.

RIBEIRO, Fábia Barbosa. Educação e ensino de História em contextos coloniais e póscoloniais. mneme - revista de humanidades, Caicó, v. 16, n. 36, p. 27-53, jan./jul. 2015. Dossiê Ensino de História

RINCÓN, Lenin González. Neocolonialismo pedagógico VS Educación libertadora nuestroamericana. In: Portal Aporrea. Disponível em: https://www.aporrea.org/educacion/a186225.html Acesso em: 01/04/2017

TIKLY, Leon. Globalisation and Education in Postcolonial World: towards a concepyual framework. Comparative Education, Vol 37, No. 2, 2001 pp. 151-171. Disponível em : http://www2.fiu.edu/ ilonl/publications/globalisation\%20and\%20education.pdf Acesso em Acesso em: 01/04/2017

Portal da Educopédia. Disponível em: http://www.educopedia.com.br/ Acesso em: $01 / 04 / 2017$ 
Portal do Instituto Brasileiro de Geografia e Estatística. Disponível em:

http://cidades.ibge.gov.br/xtras/perfil.php?codmun=330455 Acesso em: 01/04/2017

Portal da Prefeitura do Rio de Janeiro. Disponível em:

http://prefeitura.rio/web/smeel/educacao-em-numeros Acesso em: 01/04/2017 